\title{
CONTINUOUS WARM VERSUS INTERMITTENT COLD CARDIOPLEGIC INFUSION: A COMPARISON OF ENERGY METABOLISM, SODIUM-POTASSIUM ADENOSINE TRIPHOSPHATASE ACTIVITY, AND POSTISCHEMIC FUNCTIONAL RECOVERY IN THE BLOOD-PERFUSED RAT HEART
}

Yumin Qiu, MD, PhD

Manuel Galiñanes, $\mathrm{MD}, \mathrm{PhD}$

Peter S. Haddock, PhD

David J. Hearse, DSc
We used metabolic, enzymatic, and functional end points to compare the protective properties of continuous warm and intermittent cold cardioplegic infusion in isolated, blood-perfused rat hearts. After excision, hearts ( $n=12$ per group) were preserved for 3 hours by one of the following cardioplegic procedures: (1) continuous infusion of warm $\left(37^{\circ} \mathrm{C}\right)$ blood cardioplegic solution prepared by mixing Fremes' solution with rat arterial blood in a ratio of $1: 4,(2)$ continuous infusion of warm $\left(37^{\circ} \mathrm{C}\right)$ crystalloid cardioplegic solution prepared by mixing Fremes' solution with bicarbonate buffer solution in a ratio of 1:4, or (3) intermittent infusion of cold $\left(20^{\circ} \mathrm{C}\right)$ St. Thomas' Hospital cardioplegic solution number 2 infused for 3 minutes every 30 minutes during a 3-hour period of ischemia. In the continuousinfusion cardioplegic groups, the solution was infused through the aorta at a flow rate of $0.8 \mathrm{ml} \cdot \mathrm{min}^{-1} \cdot \mathrm{gm}^{-1}$ heart. At the end of the 3-hour preservation period, myocardial sodium-potassium adenosine triphosphatase activity (an index of ion-exchange activity) was assessed in six hearts in each group. The remaining hearts in each group were then aerobically perfused at $37^{\circ} \mathrm{C}$ with arterial blood (from a support rat) for a further 50 minutes, during which time they were atrially paced at 320 beats/min. At the end of this period, left ventricular developed and end-diastolic pressures were assessed with an intraventricular balloon; the hearts were then freeze-clamped and taken for the measurement of tissue adenosine triphosphate and creatine phosphate content. Hearts $(n=6)$ aerobically perfused with blood for $\mathbf{5 0}$ minutes (no cardioplegic infusion) served as control preparations. At a balloon volume of $180 \mu \mathrm{l}$, the mean final values for left ventricular developed pressure in the continuous warm blood, continuous warm crystalloid, and intermittent cold cardioplegic groups were $98 \pm 5 \mathrm{~mm} \mathrm{Hg}(p<0.05), 70 \pm 5 \mathrm{~mm} \mathrm{Hg}$, and $78 \pm 5 \mathrm{~mm} \mathrm{Hg}$, respectively. This was compared with $122 \pm 5 \mathrm{~mm} \mathrm{Hg}$ in control hearts $(p<$ 0.05 vs the rest). For left ventricular end-diastolic pressure, the corresponding values were $33 \pm 3 \mathrm{~mm} \mathrm{Hg}, 32 \pm 6 \mathrm{~mm} \mathrm{Hg}$, and $14 \pm 4 \mathrm{~mm} \mathrm{Hg}(p<$ $0.05)$, respectively. The control value was $16 \pm 3 \mathrm{~mm} \mathrm{Hg}(p<0.05$ vs continuous warm blood and continuous warm crystalloid groups). Tissue content of adenosine triphosphate was similarly reduced to approximately 50\% of control values in all groups, and creatine phosphate content fully recovered in all groups. Sodium-potassium adenosine triphosphatase activity was poorly preserved in continuous warm crystalloid-treated hearts $\left(0.012 \pm 0.003\right.$ vs $0.030 \pm 0.008 \mu \mathrm{mol}$ inorganic phosphate $\cdot \mathrm{mg}^{-1} \cdot \mathrm{min}^{-1}$
From the Department of Cardiovascular Research, The Rayne Institute, St. Thomas' Hospital, London, United Kingdom.

Supported in part by grants from STRUTH.

Received for publication Dec. 28, 1995; revisions requested Feb. 2, 1996; revisions received March 7, 1996; accepted for publication March 18, 1996.
Address for reprints: Yumin Qiu, MD, PhD, Division of Cardiology, University of Louisville, Louisville, KY 40202.

J Thorac Cardiovase Surg 1996;112:797-805

Copyright (C) 1996 by Mosby-Year Book, Inc.

$0022-5223 / 96 \$ 5.00+0 \quad \mathbf{1 2 / 1 / 7 3 5 3 1}$ 
in control preparations, $p<0.05$ ), whereas in continuous warm blood and intermittent cold cardioplegic groups $(0.032 \pm 0.015$ and $0.031 \pm 0.013$ $\mu$ mol inorganic phosphate $\cdot \mathrm{mg}^{-1} \cdot \mathrm{min}^{-1}$ ) there was no significant loss of activity. In conclusion, (1) none of the procedures conferred complete protection, (2) continuous warm blood cardioplegic infusion provided superior preservation of systolic function and intermittent cold cardioplegic infusion afforded superior protection with respect to diastolic function, and (3) both continuous warm blood and intermittent cold cardioplegic infusion similarly protected sodium-potassium adenosine triphosphatase activity and tissue adenosine triphosphate and creatine phosphate content, whereas continuous warm crystalloid cardioplegic infusion afforded poor preservation of sodium-potassium adenosine triphosphatase activity. In general, the poorest protection was afforded by continuous warm crystalloid cardioplegic infusion. (J Thorac Cardiovasc Surg 1996;112:797-805)

C ardiac pump failure is the main cause of morbidity and mortality during heart operations. A full understanding of the mechanisms that precipitate this surgically induced heart failure and the consequent development of protective interventions to prevent it are of great importance if we are to improve survival and safety during cardiac operations. Intermittent cold cardioplegic infusion with ischemic arrest is the method most widely employed for protection during cardiac operations, and although it generally affords satisfactory results, there are still a significant number of patients for whom standard protection appears to be insufficient, either because of an initial impairment of cardiac contractile function or because of a long period of ischemia required for the surgical correction. The myocardial protection obtained with intermittent cold cardioplegic infusion is based on the following principles: (1) the induction and maintenance of rapid cardiac arrest during the ischemic period, (2) the reduction of detrimental metabolic processes by the use of hypothermia, and (3) the intermittent washout of toxic metabolites by multiple infusions of the cardioplegic solution. ${ }^{1}$ It has been argued, however, that ischemic injury will still occur with this form of protection and that hypothermia itself may cause cellular damage. It has been suggested that hypothermia may cause decreased fluidity of cell membranes, which may impair transport functions, ${ }^{2}$ inactivation of sodiumpotassium adenosine triphosphatase $\left(\mathrm{Na}^{+} / \mathrm{K}^{+}\right.$ATPase) and calcium ion adenosine triphosphatase (ATPase) of the sarcoplasmic reticulum, leading to calcium overload and a loss of cell volume control, ${ }^{3,4}$ and denaturation of key proteins. ${ }^{5}$

It has recently been suggested that continuous warm cardioplegic infusion, which eliminates the need for ischemia and hypothermia, may be a better form of protection. 6,7 It has been argued that electromechanical arrest under normothermic conditions (which allows reduction of oxygen consumption by $90 \%$ ) reduces energy demand sufficiently to allow coronary flow to be safely reduced to values much lower than those required under physiologic conditions. This reduction would facilitate the surgical correction without risking ischemic injury. Early clinical studies have suggested that continuous warm cardioplegic infusion is an effective protective procedure, ${ }^{6,7}$ although a greater prevalence of neurologic problems has been reported. ${ }^{8}$ Data from controlled experimental studies comparing the protective power of continuous warm versus intermittent cold cardioplegic infusion, however, have not been reported.

Potential complications that can arise from the use of continuous blood cardioplegic infusion include embolization of microaggregates and constant exposure of the coronary vasculature to activated neutrophils. It may therefore be hypothesized that the continuous infusion of a crystalloid asanguineous solution could be a safer alternative. The aims of this study were therefore to do the following: (1) compare the myocardial protection afforded by continuous infusion of warm cardioplegic solution with that afforded by intermittent infusion of cold cardioplegic solution and (2) investigate the importance of the presence of blood elements in the protective properties of continuous warm cardioplegic infusion. To achieve this end, we employed the isolated, blood-perfused rat heart to examine the recovery of systolic and diastolic cardiac function, tissue high-energy phosphate content, and myocar- 
Table I. Composition of cardioplegic solutions

\begin{tabular}{lccc}
\hline & $\begin{array}{c}\text { Blood } \\
\text { cardioplegia } \\
(\text { mmol/L) }\end{array}$ & $\begin{array}{c}\text { Crystalloid } \\
\text { cardioplegia } \\
(\text { mmol/L) }\end{array}$ & $\begin{array}{c}\text { St. Thomas' } \\
\text { cardioplegic solution } \\
\text { number 2 (mmol/L) }\end{array}$ \\
\hline Sodium ion & 104.4 & 95.0 & 120.0 \\
Potassium ion & 10.3 & 9.6 & 16.0 \\
Calcium ion & 1.0 & 1.1 & 1.2 \\
Magnesium ion & 2.8 & 2.8 & 16.0 \\
Bicarbonate ion & 16.8 & 20.0 & 10.0 \\
Tris(hydroxymethyl)aminomethane & 12.0 & 12.0 & 0 \\
Glucose & 59.0 & 58.9 & 0 \\
pH & 7.4 & 7.4 & 7.8 \\
Hematocrit $(\%)$ & 17.8 & 0 & 0
\end{tabular}

dial $\mathrm{Na}^{+} / \mathrm{K}^{+}$-ATPase activity as end points of injury and protection.

\section{Materials and methods}

Animals. Adult male rats of the Wistar strain were used. All animals received humane care in compliance with the "Principles of Laboratory Animal Care" formulated by the National Society for Medical Research and the "Guide for the Care and Use of Laboratory Animals" prepared by the Institute of Laboratory Animal Resources and published by National Institutes of Health (NIH Publication No. 86-23, revised 1985).

Blood-perfused heart preparation. The blood-perfused, isolated rat heart preparation and techniques are described elsewhere in detail. ${ }^{9}$

Support rats. The rats ( 300 to $350 \mathrm{gm}$ body weight) were anesthetized with $60 \mathrm{mg} / \mathrm{kg}$ intraperitoneal pentobarbital and placed supine on a heated pad $\left(37.0 \pm 0.5^{\circ} \mathrm{C}\right)$. The animals were allowed to spontaneously breathe a mixture of humidified $95 \%$ oxygen plus $5 \%$ carbon dioxide, with the flow rate controlled to maintain arterial oxygen and carbon dioxide tensions within physiologic ranges. Heparin was administered intravenously at $1000 \mathrm{IU} / \mathrm{kg}$, and a femoral artery and vein were cannulated to provide an arterial blood supply to the donor heart and to allow the return of blood to the support animal. The extracorporeal circuit was primed with $5 \mathrm{ml}$ plasma substitute (Haemaccel; Hoechst UK Ltd., Behring Diagnostics Div., Middlesex, U.K.) mixed with $2 \mathrm{ml} 0.9 \%$ saline solution plus 5 $\mathrm{ml}$ blood (obtained from a donor rat). In this way, the plasma ions, blood gas values, and $\mathrm{pH}$ of the support rat were maintained within physiologic ranges. Only the levels of hemoglobin and the hematocrit were slightly reduced as a consequence of hemodilution (falling to between 10 and $12 \mathrm{gm} / \mathrm{dl}$ and $30 \%$ and $36 \%$, respectively). Arterial blood pressure and heart rate were continuously recorded.

Isolated hearts. Donor rats (220 to $280 \mathrm{gm}$ body weight) were anesthetized with diethyl ether and given $1000 \mathrm{IU} / \mathrm{kg}$ heparin intravenously. Thirty seconds later, the heart was excised and the aorta was cannulated. Blood or crystalloid cardioplegic solution was then infused, and hearts were stored according to the desired protocol. At the end of 3 hours of storage, hearts were perfused for another 50 minutes in the Langendorff mode with arterial blood from a support rat at a constant flow of $2.5 \mathrm{ml} / \mathrm{min}$. Blood was delivered to the isolated heart by means of a roller pump (Minipuls 3; Gilson, Villers-le-Bel, France), and the mean coronary perfusion pressure was continuously monitored by means of a pressure transducer connected to the aortic cannula. At the end of the experiment, cardiac systolic and diastolic function were assessed by means of an intraventricular balloon catheter that was introduced into the left ventricle through the left atrium. Pressure-volume curves were constructed by stepwise increases in balloon volumes $(30,60,90,120,150,180,210$, and $240 \mu 1)$.

Preparation and administration of cardioplegic solutions. Blood cardioplegic solution was prepared by mixing Fremes' solution (containing $30 \mathrm{mmol} / \mathrm{L}$ potassium chloride, $9 \mathrm{mmol} / \mathrm{L}$ magnesium sulfate, $12 \mathrm{mmol} / \mathrm{L}$ tris $(\mathrm{hy}-$ droxymethyl)aminomethane, $250 \mathrm{mmol} / \mathrm{L}$ glucose, and 20 $\mathrm{ml} / \mathrm{L}$ citrate-phosphate-dextrose solution) with rat arterial blood in a ratio of 1:4. Arterial blood was obtained from six to seven anesthetized donor rats through a catheter inserted into the abdominal aorta. Warm crystalloid cardioplegic solution was prepared by mixing Fremes' solution with oxygenated bicarbonate buffer (containing 11.1 $\mathrm{mmol} / \mathrm{L}$ glucose, $118.5 \mathrm{mmol}$ sodium chloride, $4.8 \mathrm{mmol} / \mathrm{L}$ potassium chloride, $1.2 \mathrm{mmol} / \mathrm{L}$ magnesium sulfate, 1.2 $\mathrm{mmol} / \mathrm{L}$ monobasic potassium phosphate, $25.0 \mathrm{mmol} / \mathrm{L}$ sodium bicarbonate, and $1.4 \mathrm{mmol} / \mathrm{L}$ calcium chloride) in a ratio of 1:4. St. Thomas' Hospital cardioplegic solution number 2 was used for intermittent cold cardioplegia. The final compositions of the cardioplegic solutions used are shown in Table I.

In hearts protected with continuous cardioplegic infusion (blood or crystalloid), the solution was delivered at $37^{\circ} \mathrm{C}$ through a thermostatic oxygenator at a flow of 0.8 $\mathrm{ml} \cdot \min ^{-1} \cdot \mathrm{gm}^{-1}$. The perfusion pressure was monitored and was less than $40 \mathrm{~mm} \mathrm{Hg}$ during the entire infusion period. In hearts protected with intermittent cold cardioplegic infusion, the solution was infused at $20^{\circ} \mathrm{C}$ for 3 minutes every 30 minutes. This moderate temperature was selected to circumvent the disadvantages and hazards of deep hypothermia while still retaining the benefits of moderate hypothermia. The temperature of the arrested hearts was continuously monitored with a thermistor probe placed into the right ventricular cavity through the pulmonary artery. Total preservation time for all hearts was 3 hours. 


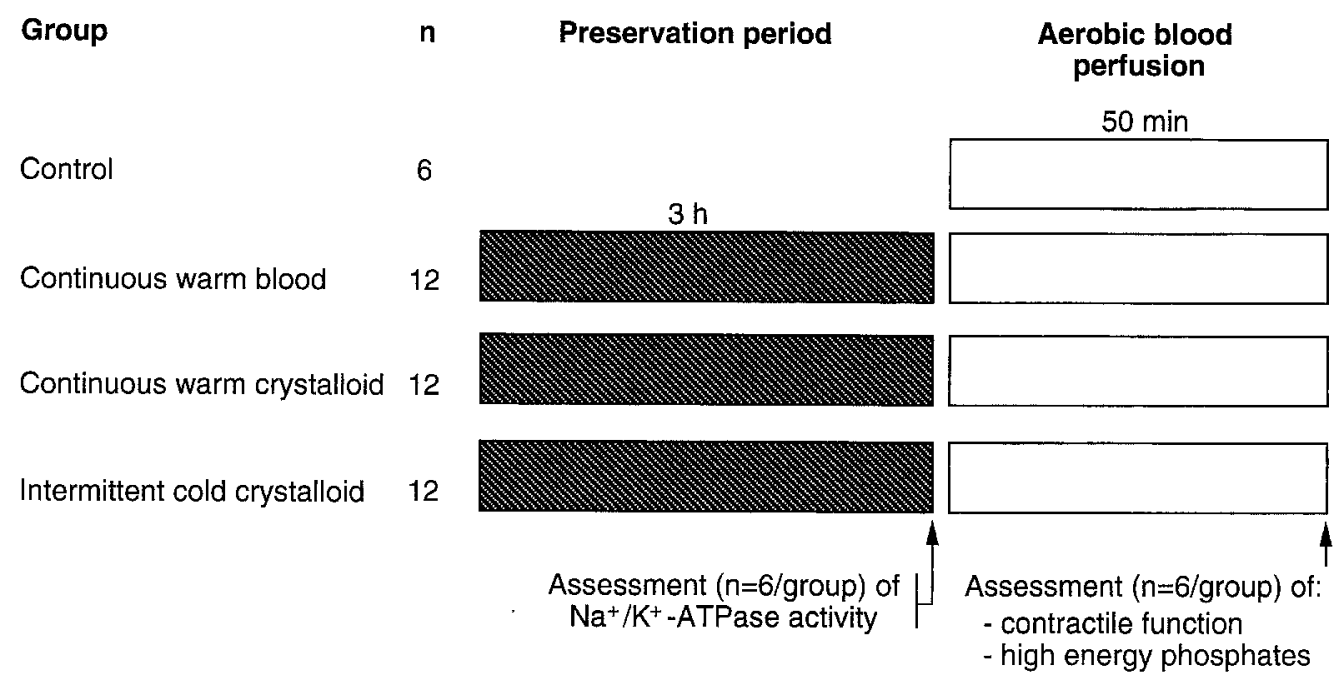

Fig. 1. Experimental protocol. Control hearts $(n=6)$ were aerobically perfused with blood from support rat. Hearts ( $n=12$ per group) in continuous warm blood cardioplegic, continuous warm crystalloid cardioplegic, and intermittent cold cardioplegic groups were preserved for 3 hours with one of these three cardioplegic interventions. At the end of this period, hearts ( $n=6$ per group) were taken for analysis of tissue $\mathrm{Na}^{+} / \mathrm{K}^{+}$-ATPase activity. Remaining hearts ( $n=6$ per group) were perfused aerobically with blood for additional 50 minutes and contractile function and high-energy phosphate levels were assessed at the end of this period.

Experimental protocol and study groups. Hearts $(n=$ 12 per group) were preserved for 3 hours with one of the following cardioplegic protocols: (1) continuous infusion of warm blood cardioplegic solution, (2) continuous infusion of warm crystalloid cardioplegic solution, or (3) intermittent infusion of cold St. Thomas' cardioplegic solution. At the end of this period, half of the hearts ( $n=$ 6 per group) were taken for the determination of $\mathrm{Na}^{+} /$ $\mathrm{K}^{+}$-ATPase activity and the other half ( $n=6$ per group) were perfused aerobically in the Langendorff mode with blood from a support rat for 50 minutes at $37^{\circ} \mathrm{C}$ (Fig. 1). During this period, hearts were paced at 320 beats $/ \mathrm{min}$. For comparative purposes, hearts $(n=6)$ not receiving cardioplegic infusion were aerobically perfused with blood for 50 minutes (Fig. 1).

Metabolite analysis. At the end of the 50 -minute perfusion period, hearts were freeze-clamped, lyophilized, pulverized, and extracted in cold $\left(4^{\circ} \mathrm{C}\right) 6 \%$ perchloric acid. Adenosine triphosphate (ATP) and creatine phosphate (CP) contents were then determined by conventional spectrophotometric methods, ${ }^{10}$ and the results were expressed micromoles per gram dry weight.

$\mathrm{Na}^{+} / \mathbf{K}^{+}$-ATPase activity assay. At the end of 3 hours of preservation, ouabain-sensitive $\mathrm{Na}^{+} / \mathrm{K}^{+}$-ATPase activity of left ventricular homogenates ( $n=6$ per group) was determined according to the method of Xie and coworkers $^{11}$ by measuring the ouabain-sensitive release of inorganic phosphate ( $\mathrm{Pi}$ ) from the hydrolysis of ATP during a 10 -minute period. Briefly, approximately $100 \mathrm{mg}$ of tissue was accurately weighed and homogenized in $1.0 \mathrm{ml} 10$ $\mathrm{mmol} / \mathrm{L}$ of tris(hydroxymethyl)aminomethane hydrochloride buffer ( $\mathrm{pH} 7.4$ at $37^{\circ} \mathrm{C}$ ) containing $1 \mathrm{mmol} / \mathrm{L}$ ethyl- enediaminetetraacetic acid. A $0.1 \mathrm{ml}$ aliquot of the homogenate was added to $0.8 \mathrm{ml}$ reaction medium of the following composition: $50 \mathrm{mmol} / \mathrm{L}$ tris(hydroxymethyl) aminomethane hydrochloride, $5 \mathrm{mmol} / \mathrm{L}$ magnesium chloride, $100 \mathrm{mmol} / \mathrm{L}$ sodium chloride, $15 \mathrm{mmol} / \mathrm{L}$ potassium chloride, and $5 \mathrm{mmol} / \mathrm{L}$ sodium azide. After 5 minutes of equilibration at $37^{\circ} \mathrm{C}$, the reaction was initiated by the addition of $0.1 \mathrm{ml} 50 \mathrm{mmol} / \mathrm{L}$ tris(hydroxymethyl)aminomethane-ATP. The reaction was stopped after 10 minutes by the addition of $0.1 \mathrm{ml}$ ice-cold $1 \mathrm{~mol} / \mathrm{L}$ trichloroacetic acid, and the resulting protein precipitate was separated by centrifugation at $1200 \mathrm{~g}$ for 3 minutes. The Pi content of the supernatant was determined according to Stanton. ${ }^{12}$ Briefly, $140 \mu \mathrm{l}$ acid molybdate solution $(0.01 \mathrm{mmol} / \mathrm{L}$ in $1.2 \mathrm{~mol} / \mathrm{L}$ sulfuric acid) was added to 40 $\mu l$ supernatant in each well of a 96 -well microplate. A further $40 \mu \mathrm{l}$ Fiske and Subbarow reagent (Sigma Chemical Co., Poole, U.K.) was added, and after $10 \mathrm{~min}$ incubation at room temperature, the absorbence of the contents of each well was measured at $600 \mathrm{~nm}$ by means of Bio-Tek Kineticalc software (Bio-Tek Instruments, Inc., Winsooski, Vt.) with 0.01 to $0.2 \mathrm{mmol} / \mathrm{L}$ potassium phosphate as a standard for $\mathrm{Pi}$. Ouabain-sensitive $\mathrm{Na}^{+} / \mathrm{K}^{+}$. ATPase activity was determined by substraction of the ATPase activity calculated in the presence of $1 \mathrm{mmol} / \mathrm{L}$ ouabain from the total ATPase activity determined in the absence of ouabain. Samples were incubated with ouabain for 15 minutes at $37^{\circ} \mathrm{C}$ before the determination of $\mathrm{Na}^{+} / \mathrm{K}^{+}$-ATPase activity. $\mathrm{Na}^{+} / \mathrm{K}^{+}$-ATPase activity was expressed as micromoles of $\mathrm{Pi}$ released per milligram of tissue per 10 minutes. Fresh rat hearts $(n=6)$ were used as control preparations. 

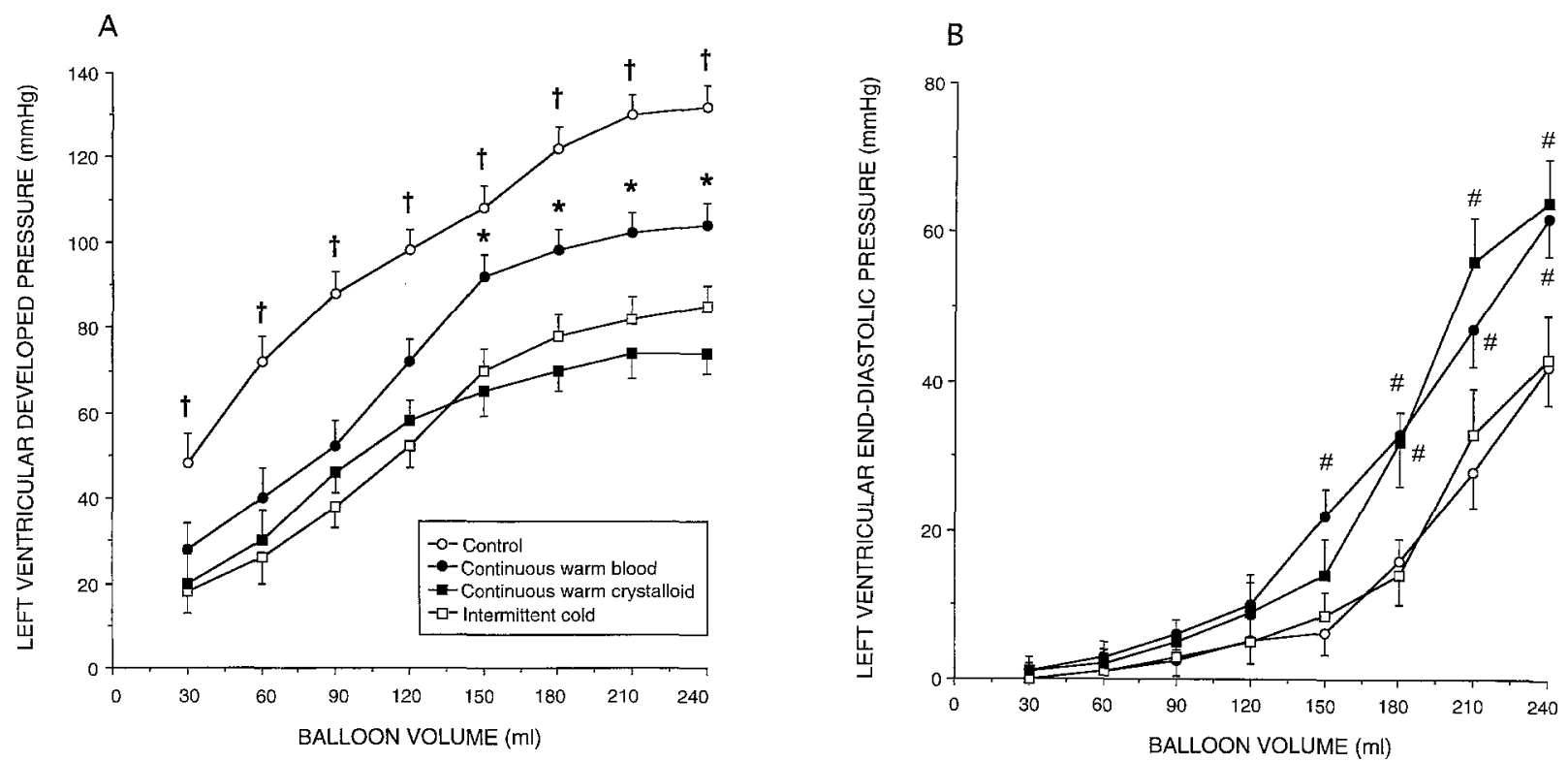

Fig. 2. Systolic (A) and diastolic (B) functions at the end of 50 minutes of aerobic blood perfusion in control hearts $(n=6)$ and hearts $(n=6$ per group) protected with continuous warm blood cardioplegic infusion, continuous warm crystalloid cardioplegic infusion, and intermittent cold cardioplegic infusion. Data presented as mean \pm SEM. Asterisk indicates $p<0.05$ compared with intermittent cold cardioplegic and continuous warm crystalloid cardioplegic groups; dagger indicates $p<0.05$ compared with all other groups; hatch mark indicates $p<0.05$ compared with intermittent cold cardioplegic and control groups.

Statistical analysis. All results were expressed as the mean ( \pm standard error of the mean [SEM]). Analysis of variance was employed for multiple comparisons. When a significant $F$ value was obtained, comparison between means was carried out with Tukey's test. A difference was considered statistically significant at $p$ values less than 0.05 .

\section{Results}

Contractile function. Fig. $2(A)$ shows that systolic function at all balloon volumes had deteriorated significantly by the end of the experimental period in all cardioplegic groups when compared with control hearts. Hearts protected with continuous warm blood cardioplegic infusion, however, tended to exhibit better function than those treated with continuous warm crystalloid or intermittent cold cardioplegic infusion, and this difference achieved statistical significance at balloon volumes of 150 to $240 \mu \mathrm{l}$. For example, at a balloon volume of $180 \mu \mathrm{l}$, the mean value for left ventricular developed pressure was $122 \pm 5 \mathrm{~mm} \mathrm{Hg}$ in control hearts, whereas left ventricular developed pressures in hearts perfused with continuous warm crystalloid or intermittent cold cardioplegic solution, were only 70 \pm 5 and $78 \pm 5 \mathrm{~mm} \mathrm{Hg}$, respectively. In hearts perfused continuously with warm blood cardioplegic solution, the value was $98 \pm 5 \mathrm{~mm} \mathrm{Hg}(p<0.05)$.

In contrast to the results for systolic function, diastolic function (Fig. 2, B) was significantly impaired in hearts perfused with continuous warm blood and crystalloid cardioplegic solutions when compared with control hearts. Diastolic function was fully preserved, however, in hearts treated with intermittent cold cardioplegic infusion. For the example of $180 \mu \mathrm{l}$ balloon volume, the mean values for left ventricular end-diastolic pressure in continuous warm blood and crystalloid cardioplegic groups were $33 \pm 3$ and $32 \pm 6 \mathrm{mmHg}$, whereas the value in hearts protected with intermittent cold cardioplegic infusion was $14 \pm 4 \mathrm{~mm} \mathrm{Hg}$, a value that did not differ significantly from that of controls hearts $(16 \pm$ $3 \mathrm{~mm} \mathrm{Hg}$ ).

Coronary perfusion pressure. Fig. 3 shows the profile for coronary perfusion pressure during the 50 minutes of aerobic blood perfusion in all groups. Because hearts were perfused at a constant flow rate, this index reflects changes in coronary vascular resistance. The profiles of coronary perfusion pressure were similar in all study groups. At the end of the 50 -minute perfusion period, the mean values of 


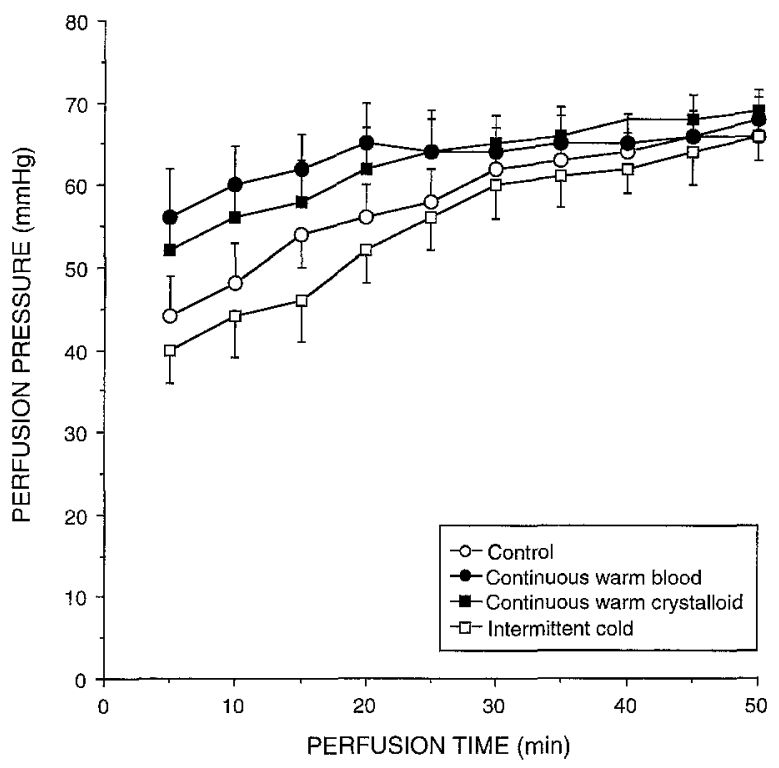

Fig. 3. Perfusion pressure during 50 minutes of aerobic blood perfusion in control hearts $(n=6)$ and hearts $(n=$ 6 per group) protected with continuous warm blood cardioplegic infusion, continuous warm crystalloid cardioplegic infusion, and intermittent cold cardioplegic infusion. Data presented as mean \pm SEM.

coronary perfusion pressure were $63 \pm 3,68 \pm 2.6$, and $59 \pm 4 \mathrm{~mm} \mathrm{Hg}$ in the continuous warm blood cardioplegic infusion, crystalloid cardioplegic infusion, and intermittent cold cardioplegic infusion groups, respectively. The corresponding value in control hearts was $61 \pm 3 \mathrm{~mm} \mathrm{Hg}$ ( $p$ not significant).

Tissue high-energy phosphate content. As shown in Fig. $4(A)$, the tissue content of ATP in all cardioplegic groups was depleted by more than $50 \%$ $(11.7 \pm 1.2,9.8 \pm 1.1$, and $8.2 \pm 1.0 \mu \mathrm{mol} / \mathrm{gm}$ dry weight in the continuous warm blood cardioplegic infusion, crystalloid cardioplegic infusion, and intermittent cold cardioplegic infusion groups, respectively) compared with the value obtained in aerobic control preparations $(20.5 \pm 1.2 \mu \mathrm{mol} / \mathrm{gm}$ dry weight; $p<0.05$ in all cases). The contents of $C P$ (Fig. $4, B$ ) were similar in all cardioplegic groups and in control hearts.

$\mathrm{Na}^{+} / \mathbf{K}^{+}$-ATPase activity. As shown in Fig. 5, at the end of the experimental period hearts receiving continuous warm blood and intermittent cold cardioplegic infusion had myocardial $\mathrm{Na}^{+} / \mathrm{K}^{+}$-ATPase activities $(0.032 \pm 0.015$ and $0.031 \pm 0.013 \mu \mathrm{mol}$ $\mathrm{Pi} \cdot \mathrm{mg}^{-1} \cdot \mathrm{min}^{-1}$, respectively) similar to that observed in control hearts perfused aerobically with

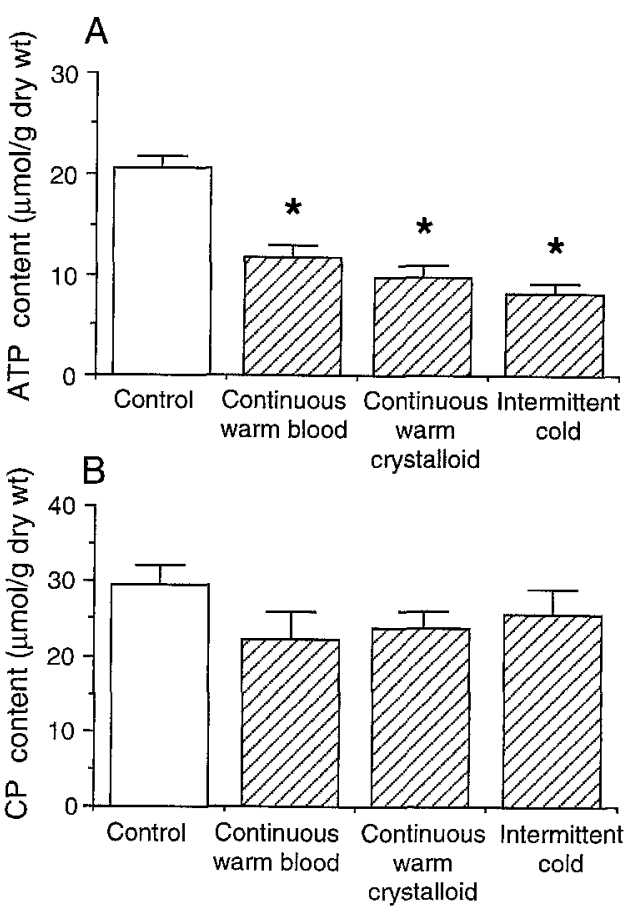

Fig. 4. Tissue ATP (A) and CP (B) levels at end of 50 minutes of aerobic blood perfusion in control hearts $(n=$ 6 ) and hearts ( $n=6$ per group) protected with continuous warm blood cardioplegic infusion, continuous warm crystalloid cardioplegic infusion, and intermittent cold cardioplegic infusion. Data presented as mean \pm SEM. Asterisk indicates $p<0.05$ compared with control hearts.

blood for 50 minutes $(0.30 \pm 0.008 \mu \mathrm{mol}$ $\mathrm{Pi} \cdot \mathrm{mg}^{-1} \cdot \min ^{-1}, p$ not significant $)$. Hearts receiving continuous warm crystalloid cardioplegic infusion, however, exhibited significantly decreased $\mathrm{Na}^{+} / \mathrm{K}^{+}$-ATPase activity $(0.012 \pm 0.003 \mu \mathrm{mol}$ $\left.\mathrm{Pi} \cdot \mathrm{mg}^{-1} \cdot \min ^{-1} ; p<0.05\right)$ compared with control hearts and with hearts treated with continuous warm blood and intermittent cold cardioplegic infusions.

\section{Discussion}

The results of this study with the blood-perfused rat heart indicate that although none of the three interventions studied conferred full protection of contractile function, (1) systolic function was best preserved with continuous warm blood cardioplegic infusion, whereas diastolic function was best protected with intermittent cold crystalloid cardioplegic infusion; (2) vascular resistance was maintained within control values with each of the interventions; (3) tissue ATP content was equally depressed in all cases; and (4) $\mathrm{Na}^{+} / \mathrm{K}^{+}$-ATPase activity was unaf- 
fected by either the temperature of the cardioplegic solution or the use of continuous versus intermittent infusion. $\mathrm{Na}^{+} / \mathrm{K}^{+}$-ATPase activity was significantly depressed when blood was replaced by a crystalloid solution during continuous warm cardioplegic infusion.

Continuous versus intermittent cardioplegic administration. Recently, continuous warm blood cardioplegic infusion has been proposed as a means of avoiding the risk of deleterious consequences of ischemia and the detrimental effects of hypothermia associated with conventional cardioplegic procedures. Initial clinical results have been promising, and continuous warm cardioplegic infusion has been adopted for use by a significant number of cardiac surgeons. It has been reported, however, that patients protected with continuous warm blood cardioplegic infusion have a higher prevalence of neurologic events and perioperative strokes, ${ }^{8}$ greater prevalence of hyperkalemia, ${ }^{13}$ and greater activation of neutrophils. ${ }^{14}$ There is currently no conclusive evidence for the superiority of continuous warm cardioplegic infusion. ${ }^{15}$ Furthermore, no experimental animal data support the superiority of continuous warm blood cardioplegic infusion with respect to the more widely used intermittent cold cardioplegic infusion. This study is the first to compare the protective effects of the two procedures in a controlled experimental setting. We have shown that neither continuous warm blood nor intermittent cold crystalloid cardioplegic infusion is able to afford full protection against the loss of contractile function and high-energy phosphates that occurs when hearts are subjected to a long period ( 3 hours) of cardiac arrest with no coronary flow or low coronary flow. We have also demonstrated that neither procedure appears consistently superior when other indexes of protection are used. Although continuous warm blood cardioplegic infusion appears to afford better protection when systolic function is the end point, intermittent cold cardioplegic infusion appears to be superior when diastolic function is the end point. When highenergy phosphate levels are used as the end point, the procedures appear identical.

An unexpected finding in this study was the reduction in ATP content that was detected in hearts that were protected with continuous warm cardioplegic infusion. This occurred despite cardioplegic protection and the provision of a residual coronary flow rate that has been shown to be more than sufficient to meet the global oxygen demand of

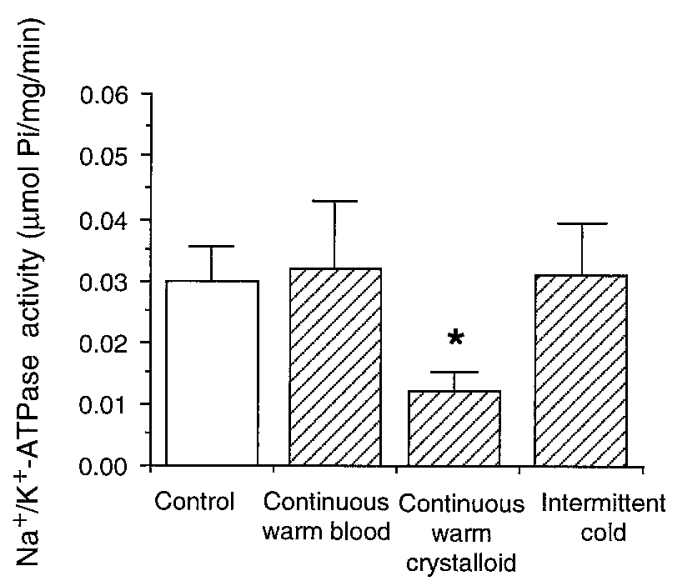

Fig. 5. Tissue $\mathrm{Na}^{+} / \mathrm{K}^{+}$-ATPase activity in fresh control hearts $(n=6)$ and hearts ( $n=6$ per group) at the end of 3 hours of protection with continuous warm blood cardioplegic infusion, continuous warm crystalloid cardioplegic infusion, and intermittent cold cardioplegic infusion. Data presented as mean \pm SEM. Asterisk indicates $p<$ 0.05 compared with all other groups.

the arrested heart. ${ }^{16,17}$ One possible explanation for this finding could be the heterogeneous redistribution of low levels of flow resulting in hypoperfusion (and thus ischemia) in some regions of the heart. This possibility is supported by reports ${ }^{18}$ of ultrastructural damage and the existence of areas without reflow in human hearts been protected with continuous blood cardioplegic infusion. If this heterogeneous redistribution of flow is confirmed, the problem may be particularly relevant in the presence of myocardial hypertrophy or severe coronary artery stenosis. If such were to prove the case, then the recommended flow rate for continuous warm cardioplegic infusion might need to be increased. Such a change could, however, create impractical operative conditions. It is interesting to note that a low perfusion pressure during continuous infusion of warm cardioplegic solution, as occurred in our study, may aggravate any existing heterogenous redistribution of flow. Adequacy of flow rate, adequacy of perfusion pressure, and their relationship clearly need further investigation.

The temperature of cardioplegic solution. The disadvantages and hazards of hypothermia are well known, but they are far outweighed by the advantages when used as an adjunct to cardioplegic infusion. ${ }^{1}$ A major contributor to hypothermia-induced cellular injury is ionic redistribution and cell swelling. A key mechanism responsible for cold swelling is thought to be inactivation by hypothermia of 
sarcolemmal $\mathrm{Na}^{+} / \mathrm{K}^{+}$-ATPase, a condition that would tend to exacerbate intracellular sodium overloading and (where ischemia and reperfusion are involved) predispose toward calcium overloading during reperfusion. In contrast to what might be expected, however, $\mathrm{Na}^{+} / \mathrm{K}^{+}$-ATPase activity was normal in the crystalloid cardioplegic group.

Deterioration of diastolic function after openchest operations has been reported. ${ }^{19}$ One surprising finding of our study was that diastolic function was better preserved in the cold intermittent cardioplegic group than in the continuous normothermic blood cardioplegic group. Furthermore, the coronary vascular resistance in hearts that had been subjected to hypothermia was similar to that of control hearts and hearts protected with continuous warm cardioplegic infusion. These results suggest that hypothermia, despite the changes induced in the physical properties of the various cell elements, may not adversely alter the lusitropic properties of the contractile apparatus or the integrity of the vasculature. Our results suggest that moderate $\left(20^{\circ} \mathrm{C}\right)$ hypothermia may in itself have no detrimental effects when used as an adjunct to intermittent cardioplegic infusion.

Importance of blood components in continuous cardioplegic infusion. Although it is natural to assume that blood would be the best vehicle for the delivery of continuous warm cardioplegic protection, its use may not be without hazard. The exposure of blood to foreign surfaces (necessary in the preparation and administration of a blood cardioplegic solution) may promote the formation of microaggregates and activation of neutrophils, both of which could negatively influence the ability of blood cardioplegic solutions to preserve tissue viability. On the basis of this consideration, it could be argued that crystalloid cardioplegic solutions offer better protection than blood-based solutions when used in a continuous-infusion mode. This study has shown, however, that continuous warm cardioplegic infusion of a crystalloid solution is not as effective as continuous warm infusion of blood in preserving systolic function. This difference was not related to tissue content of high-energy phosphates, because tissue ATP and CP levels were similar in both cases. The loss of contractile function with continuous crystalloid cardioplegic infusion could, however, be related to the apparent loss of $\mathrm{Na}^{+} / \mathrm{K}^{+}$-ATPase activity observed at the end of the preservation period in hearts protected with continuous warm crystalloid cardioplegic infusion. Such a loss of
$\mathrm{Na}^{+} / \mathrm{K}^{+}$-ATPase activity may have adverse effects on intracellular sodium and calcium homeostasis and thus may adversely affect contractile activity.

Clinical implications and future directions. Continuous warm blood cardioplegic infusion has been adopted for routine use by a substantial number of cardiac surgeons. It has been suggested that this procedure offers a greater margin of safety than other forms of myocardial protection, despite the absence of rigorous surgical trials and the lack of detailed experimental studies supporting its superiority. Although limited by the use of the bloodperfused rat heart, this study draws attention to the fact that warm continuous blood cardioplegic infusion may appear better than, worse than, or similar to intermittent, cold cardioplegic infusion, depending on the indexes used for assessment. Clearly more work is required to resolve this controversy; as illustrated by this study, future investigations should consider the dangers of employing a single end point in the assessment of injury and protection.

\section{REFERENCES}

1. Hearse DJ, Braimbridge MV, Jynge P. Principles of cardioplegia. In: Protection of the ischemic myocardium: cardioplegia. New York: Raven Press, 1981:151-326.

2. McMurchie EJ, Raison JK, Cairncross KD. Temperatureinduced phase changes in membranes of heart: a contrast between the thermal response of poikilotherms and homeotherms. Comp Biochem Physiol [B] 1973;44:1017-26.

3. Martin DR, Scott DF, Downer GL, Belzer FO. Primary cause of unsuccessful liver and heart preservation: cold sensitivity of the ATP-ase system. Ann Surg 1972;175:111-7.

4. MacKnight $A C$, Leaf $A$. Regulation of cellular volume. Physiol Rev 1977;57:510-73.

5. Rahn H, Reeves RB, Howell BJ. Hydrogen ion regulation temperature and evolution. Am Rev Respir 1975;112:165-72.

6. Salerno TA, Houck JP, Barrozo CA, Panos A, Christakis GT, Abel JG, et al. Retrograde continuous warm blood cardioplegia: a new concept in myocardial protection. Ann Thorac Surg 1991;51:245-7.

7. Christakis GT, Koch JP, Deemar KA, Fremes SE, Sinclair L, Chen E, et al. A randomized study of the systemic effects of warm heart surgery. Ann Thorac Surg 1992;54:449-57.

8. Martin TD, Craver JM, Gott JP, Weintraub WS, Ramsay J, Mora CT, et al. Prospective, randomized trial of retrograde warm blood cardioplegia: myocardial benefit and neurologic threat. Ann Thorac Surg 1994;57:298-302.

9. Qiu Y, Manché A, Hearse DJ. Contractile and vascular consequences of blood versus crystalloid cardioplegia: studies in the blood perfused isolated rat heart. Eur $\mathbf{J}$ Cardiothorac Surg 1993;7:137-45.

10. Hearse DJ. Microbiopsy metabolite and paired flow analysis: a new rapid procedure for homogenization, extraction and analysis of high energy phosphates and other intermediates without any errors from tissue loss. Cardiovasc Res 1984;18: 384-90.

11. Xie ZJ, Askari A, Huang WH, Klaunig JE. Studies on the 
specificity of the effects of oxygen metabolites on cardiac sodium pump. J Mol Cell Cardiol 1990;33:911-20.

12. Stanton MG. Colorimetric determination of inorganic phosphate in the presence of biological material and adenosine triphosphate. Anal Biochem 1968;22:27-34.

13. Kao YJ, Mian T, Kleinman S, Racz GB. Hyperkalaemia: a complication of warm heart surgery. Can J Anaesth 1993;40: $67-70$.

14. Menasché $P$, Peynet J, Larivière J, Tronc F, Piwnica A, Bloch $\mathrm{G}$, et al. Does normothermia during cardiopulmonary bypass increase neutrophil-endothelium interactions? Circulation 1994;90(5 Pt 2):II275-9.

15. Guyton RA. Warm blood cardioplegia: benefits and risks. Ann Thorac Surg 1993;55:1071-2.

16. Buckberg GD, Brazier JR, Nelson RL, Goldstein S, McCon- nell DH, Cooper N. Studies of the effects of hypothermia on regional blood flow and metabolism during cardiopulmonary bypass. J Thorac Cardiovasc Surg 1977;75:87-94.

17. Ikonomidis JS, Yau TM, Weisel RD, Hayashida N, Fu X, Komeda $\mathrm{M}$, et al. Optimal flow rates for retrograde warm cardioplegia. J Thorac Cardiovasc Surg 1994;107:510-9.

18. Rainio P, Sormunen R, Lepojärvi M, Nissinen J, Kaukoranta $P$, Peuhkurinen $\mathrm{K}$. Ultrastructural changes during continuous retrograde warm and mild hypothermic blood cardioplegia for coronary bypass operations. J Thorac Cardiovasc Surg 1995;110:81-8.

19. McKenney PA, Apstein CS, Mendes LA, Connelly GP, Aldea GS, Shemin RJ, et al. Increased left ventricular diastolic chamber stiffness immediately after coronary artery bypass surgery. J Am Coll Cardiol 1994;24:1189-94. 